\title{
Sheet-bulk metal forming - forming of functional components from sheet metals
}

\author{
Marion Merklein ${ }^{\text {a }}$, Daniel Gröbel, Maria Löffler, Thomas Schneider, and Philipp Hildenbrand \\ Institute of Manufacturing Technology, Friedrich-Alexander-Universität Erlangen-Nürnberg (FAU), \\ Egerlandstr. 13, 91058 Erlangen, Germany
}

\begin{abstract}
The paper gives an overview on the application of sheet-bulk metal forming operations in both scientific and industrial environment. Beginning with the need for an innovative forming technology, the definition of this new process class is introduced. The rising challenges of the application of bulk metal forming operations on sheet metals are presented and the demand on a holistic investigation of this topic is motivated. With the help of examples from established production processes, the latest state of technology and the lack on fundamental knowledge is shown. Furthermore, perspectives regarding new research topics within sheet-bulk metal forming are presented. These focus on processing strategies to improve the quality of functional components by the application of processadapted semi-finished products as well as the local adaption of the tribological system.
\end{abstract}

\section{Motivation}

The saving of resources is an important aspect for the $21^{\text {st }}$ century to reduce the greenhouse gas emissions and slow down the climate change. For the automotive industry these challenges can be met by lightweight design. For example, reducing the weight of a compact car about by $100 \mathrm{~kg}$ leads to a lower fuel consumption of $0.151 / 100 \mathrm{~km}$ [1]. In consequence, a holistic approach considering all aspects of automotive lightweight design is needed. Regarding for instance the car's engine, a downsizing saves weight, however leads to higher loads for the individual components at an equal performance [2]. For components from this part of the car, like a synchronizer ring, this leads to an integration of functional elements for weight reduction and the application of different materials for increasing the component's strength [3]. Using forming processes is ideal for an ecological mass production of these components. However, new technologies or processes have to be developed because, by using existing ones these components cannot be manufactured at all or only by having long process chains and higher costs [4]. Applying bulk forming operations on sheet metals, defined as sheet-bulk metal forming (SBMF), is a promising approach for the manufacturing of these complex components at shortened process chains and simultaneously improved material efficiency [3].

\footnotetext{
${ }^{\text {a }}$ Corresponding author: marion.merklein@fau.de
}

This is an Open Access article distributed under the terms of the Creative Commons Attribution License 4.0, which permits unrestricted use, distribution, and reproduction in any medium, provided the original work is properly cited. 


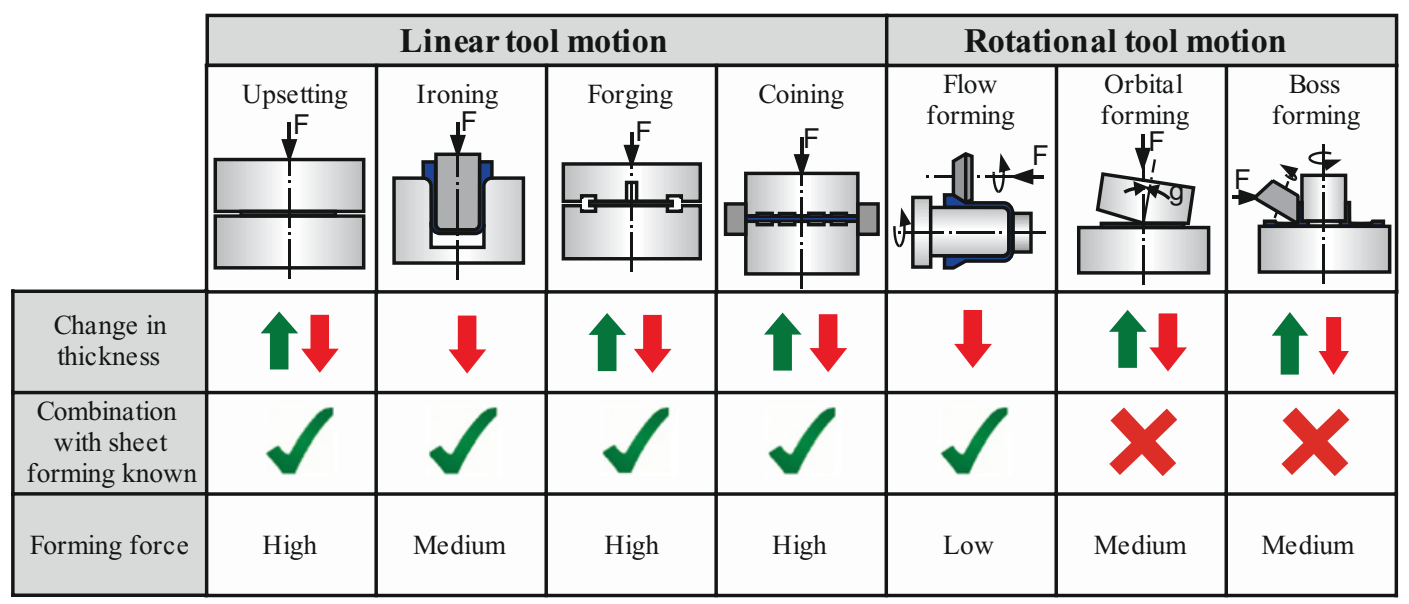

Figure 1. Process classification and characteristics of common sheet-bulk metal forming operations [6].

\section{Sheet-bulk metal forming}

\subsection{Definition and classification of sheet-bulk metal forming}

Sheet-bulk metal forming is defined as forming of sheets with an intended three-dimensional material flow as in bulk forming processes [3]. This new process class includes several conventional forming operations that are combined and extended in their application, and are oftentimes conducted in conjunction with conventional sheet forming processes. One central characteristic is given by the complex interaction between forming zones of high and low strains that possess three-dimensional, as well as two-dimensional stress and strain states. All forming operations are applied on semi-finished parts of 1 to $5 \mathrm{~mm}$ thickness with the intention to form local shape elements projecting out of the plane which are in the dimension of the sheet thickness [3]. Besides manufacturing of functional integration, SBMF can also be used to redirect material on sheets in order to produce semi-finished parts with tailored properties.

In [5] forming processes are categorised in respect to the stress states during the forming operation. However, this classification is not applicable to sheet-bulk metal forming processes since characteristics of multiple processes can merge in some cases [3]. Furthermore the geometry of the semi-finished parts in question is not respected. In order to solve this challenge, a classification that enables a distinction of possible processes by the tool motion in use is proposed in [3]. As Fig. 1 shows, upsetting, ironing, forging and coining can be assigned to the group of linear motions whereas rotational movement can be found in flow forming, orbital forming and boss forming. Furthermore all processes can be descripted by the resulting change in sheet thickness, the possibility of combinations with sheet forming operations and by the demand on forming force. Process forces are particularly dependent on the effective contact area between workpiece and tool during the forming operation. High contact areas result in high process forces, whereas small contact areas demand less force. Due to this circumstance upsetting, forging and coining possess the highest force demands due to their typically large contact areas. One strategy to overcome this challenge is the use of incremental forming processes like orbital forming or flow forming. Such processes are characterized by small but moving contact and forming zone.

As listed in Fig. 1, it is possible to both locally reduce or heighten sheet thickness in most sheet-bulk metal forming processes. Additionally, a combination with conventional sheet forming operations is predominantly possible. The circumstance that both aspects apply to forging and upsetting makes those operations particularly promising methods if complex sheet products of high functional integrations 

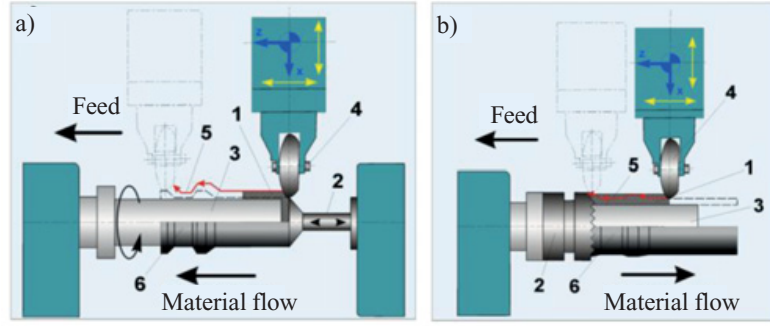

Figure 2. a) Forward flow forming and b) backward flow forming [8].

have to be produced. However, a typical characteristic of functional elements are their small dimensions in comparison to the total dimensions of the part. Subsequently, the forming of such structures results in complex locally restricted three dimensional forming zones. These zones typically possess high plastic strains that are surrounded by large areas of non-strain hardened material. Due to this interrelation, the material flow during the forming operation gets progressively more pronounced in direction of the strain gradient and impedes the forming of the functional elements. Therefore, controlling the material flow in sheet-bulk metal forming processes is crucial for the proper forming of functional elements. Exemplarily, two sheet-bulk metal forming processes listed in Fig. 1 are presented in the following chapter with focus on the occurring material flow.

\subsection{Examples of sheet-bulk metal forming processes}

\subsubsection{Flow forming}

Flow forming is according to [6] an incremental sheet-bulk metal forming process with a rotational tool movement to reduce the sheet thickness at low forming forces. It is characterized by a local forming zone which is restricted by two partially contacting tools [7]. This enables the manufacturing of axially symmetrical parts with high surface quality and precision [8]. The parts can either be conical or cylindrical depending on the mandrel geometry. A schematic setup is depicted in Fig. 2 with the two variants forward and backward flow forming. In forward flow forming the material flow is in direction of the feed motion whereas for backward flow forming the material flow is in opposite direction.

For both variants the tool is fixed by a mandrel whereas the rolling tool is positioned at the workpiece and creates an axial displacement of the material while the inner diameter is not changed. Thus, a defined variation of the wall thickness is possible at a small, locally restricted deformation zone between the rolls and the workpiece [9]. One main goal in flow forming is the minimization of the tangential material flow to prevent an increase of the inner diameter which can be realized by specifically adjusting process parameters like feed motion, rolling tool geometry or axial offset [10]. The small forming zone results in a complex stress and strain distribution [9] with high contact stresses limiting the desired axial material flow. Regarding the primary forming zone which is the zone at the contact with the rolling tool, a triaxial compressive stress state occurs whereas the secondary forming zone, the zone in front of the primary zone shows a biaxial stress state [7]. This leads to a material displacement in axial and tangential direction from the primary to the secondary forming zone resulting in an accumulation and bulging of the material [7] as well as an overall lengthening of the component. The feed motion of the rolling tool transfers the secondary forming zone into the primary forming zone and the accumulated material is levelled. By using flow forming processes, a reduction of the initial wall thickness up to $90 \%$ can be achieved which results in a high work hardening and reduced notch sensitivity [3]. Forming functional elements like internal gearings can be achieved by using mandrels with a negative mould of the target geometry and a rolling of the inner diameter into the moulds [11]. 

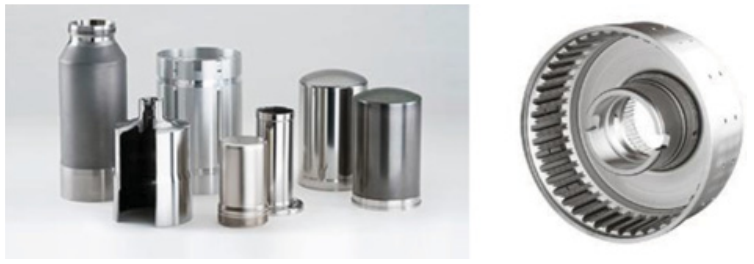

Figure 3. Thin-walled components with functional elements manufactured by flow forming [14].

a)
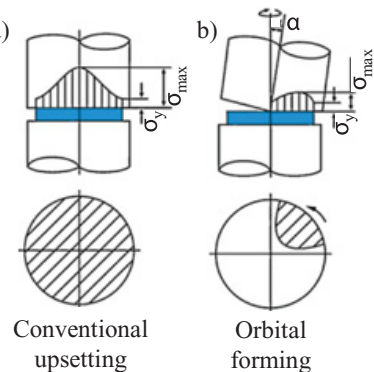

Figure 4. a) Conventional upsetting and b) orbital forming [18].

Flow forming is industrially used for the manufacturing of thin-walled tubular components, as presented in Fig. 3. The main advantages are a high geometric flexibility, low tool loads [12] as well as a high material efficiency and low production costs [13].

\subsubsection{Orbital forming}

Orbital forming originated as a cold bulk-forming process [15] and can be classified as an incremental forming process with a rotational tool movement. Due to the tilted upper die and the typical tumbling motion the contact zone between tool and workpiece can be reduced up to $70 \%$ compared with conventional upsetting [16], see Fig. 4. This results in lower forming forces necessary [16] and thus enables an enhancement of process limits. The tumbling motion leads to a rolling of the workpiece under compressive stresses in a locally restricted forming zone which moves over the surface [17].

The rotating and locally restricted forming zone causes in an inhomogeneous radial and tangential distribution of stresses on the workpiece side contacting the rotating upper die whereas the opposite workpiece side shows a predominantly homogeneous distribution [19]. This leads to radial and tangential material flow in orbital forming with the tangential material flow dominating [19]. In contrast to conventional upsetting with a material flow in radial and axial direction resulting in widening and thinning of the workpiece, the tangential material flow causes both a thinning and thickening of the workpiece [20]. In addition, the material flow is influenced by the friction between tool and workpiece. In conventional upsetting, the radial material flow is impeded resulting in increased normal contact stresses towards the workpiece's centre. The smaller contact area in orbital forming however, leads to less variation of contact stresses which benefits the material flow [18]

Orbital forming is industrially used for the manufacturing of axially symmetric near net-shape components like the ones shown in Fig. 5. Complex shaped components with high strength and good tooth quality can by manufactured by using orbital forming in a multi-stage process chain [21]. 

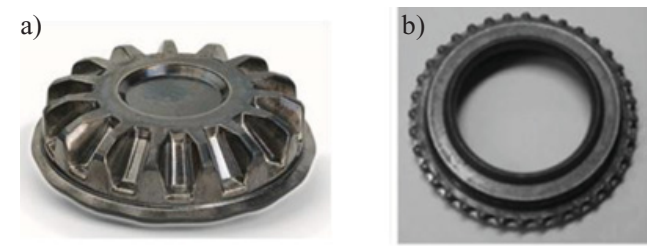

Figure 5. Components manufactured by orbital forming - a) bevel gear [21] and b) gear wheel [22].

a) Forming concept
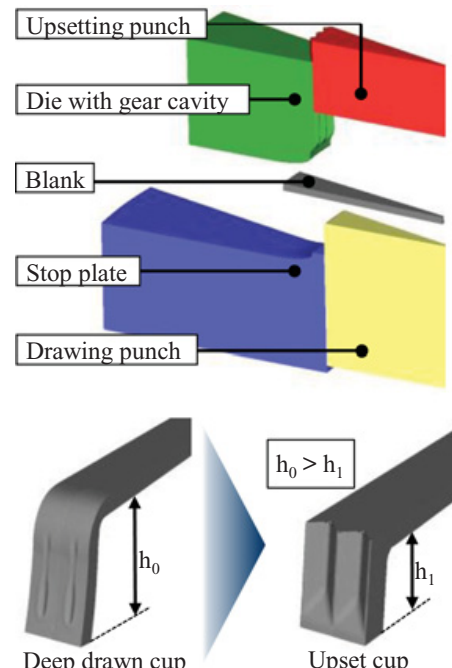

Deep drawn cup

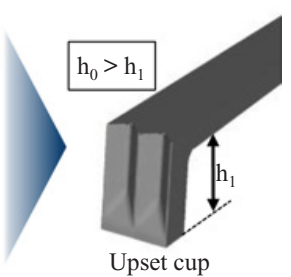

b) Resulting product geometry

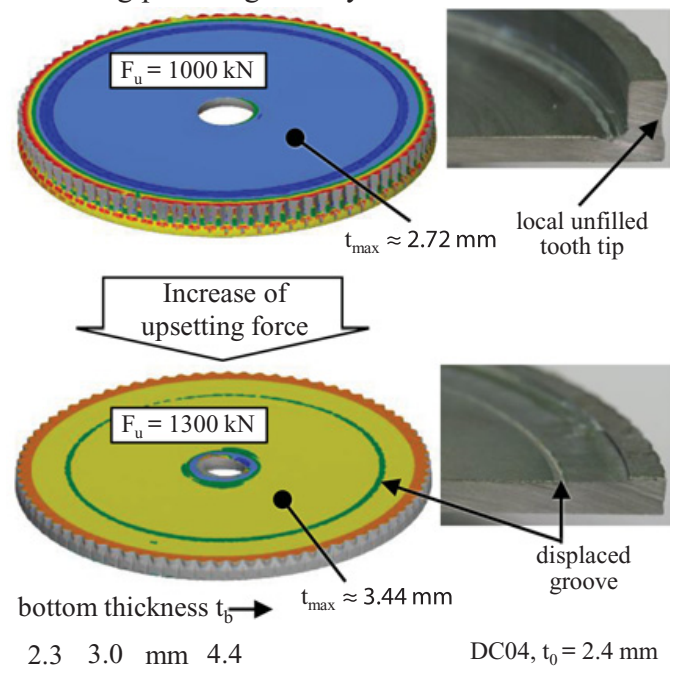

Figure 6. Deep drawing and upsetting of geared sheet metal components - a) analysis of the material flow and b) resulting product geometry with increasing forming forces.

\section{Innovative solutions for controlling the material flow in sheet-bulk metal forming processes}

In the following chapter the necessity of controlling the material flow for two sheet-bulk metal forming processes is presented. The processes are a single stage deep drawing and upsetting process for manufacturing thin-walled cups with an external gearing and a cold forging process for forming functional elements. Additionally, two solutions for improving the components quality by directing the material flow are shown: the local adaption of tribological conditions and the application of tailored blanks.

\subsection{Boundary conditions for presented sheet-bulk metal forming processes}

A well-known application of SBMF is the process combination of deep drawing and upsetting. In most approaches, in multi-stage tool set-ups, a cup is deep drawn and the cup wall is thickened circumferential or locally, if features like gear teeth are required. To shorten the process chain, a single-stage forming sequence was developed to form geared sheet metal components in a single tool at just one press stroke, see Fig. 6a [23]. The process analyses on this topic reflect one of the main challenges of SBMF, the control of the material flow. At moderate upsetting forces, buckling of the cup wall occurs, which results in inhomogeneous thickening and hence locally unfilled areas of the gear teeth and a groove 


\section{MATEC Web of Conferences}

a) Process set-up

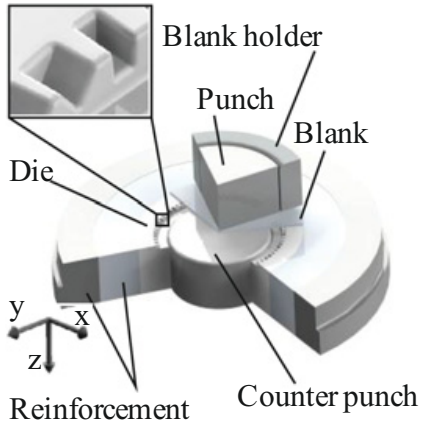

b) Resulting geometry

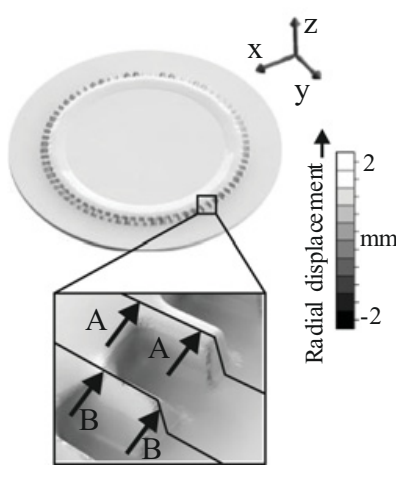

Rectangular Element

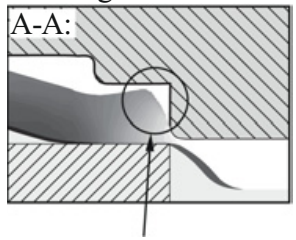

insufficient mould filling

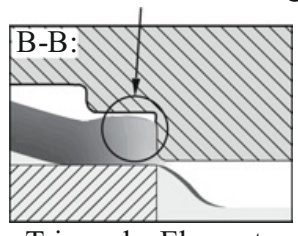

Triangular Element

Figure 7. a) Cold forging of functional elements of different shape out of a blank. b) Resulting insufficient filling of the mould due to radial material flow in the sheet plane.

at the transition from the cup bottom to the wall. With increasing upsetting forces, the die filling is improved, but a material flow around the corner into the soft cup bottom is induced simultaneously. The undesired material flow into the bottom results in a compression of the complete cup wall as well as a displacement of the groove radially inwards and a strong thickening of the bottom area. To improve the product properties, a simple increase of forming forces is not an adequate approach, but the control of the material flow has to be considerably improved.

Another application of sheet-bulk metal forming is a cold forging to form functional elements on sheet metal. Figure 7 shows a process variant that enables the forming of triangular and rectangular elements on a circular sheet. As Fig. 7a shows, the process consists of a reinforced die with geometrically differing cavities that resemble the negative geometry of the functional elements. The forming operation is initiated by a punch movement in z-direction after a centrally positioned blank has been placed on the die and results in the final product geometry displayed in Fig. 7b. Since the high plastic strain forming zone is located only in the area of the tool cavities, a distinct material flow into the non strain-hardened sheet plane in positive and negative radial direction influences the forming of the elements, as can be seen in Fig. 7b. The radial material flow leads to a bulging of the sheet in the centre and simultaneous insufficient filling of the tool moulds. Current research revealed that this effect is dependent on the chosen geometry of the cavity in question, as well as on the arrangement of the moulds [24].

As shown above, controlling the material flow in sheet-bulk metal forming processes is crucial for the proper filling of functional elements and thus ensures the desired product quality with major influencing factors being the temporally and locally varying load conditions. Thus, the investigation and understanding of the material flow is of major importance to achieve the best possible process control and to guarantee an acceptable product quality. This leads to the development of solutions for controlling the material flow. Two innovative solutions, the local adaption of the tribological conditions and the application of process adapted semi-finished parts are presented in the following chapter.

\subsection{Solutions for controlling the material flow}

\subsubsection{Locally adapted tribological conditions as a method to influence material flow}

Promising approaches to overcome the challenge of controlling the material flow are adapted tribological conditions. Investigations on this topic have already shown the interaction of material flow and 


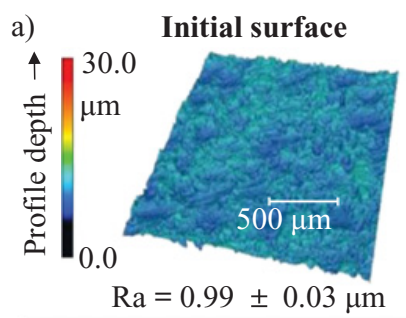

\begin{tabular}{|c|c|c|c|}
\hline \multirow{2}{*}{\multicolumn{2}{|c|}{$\begin{array}{l}\text { Topography } \\
\text { Confocal laserscanning }\end{array}$}} & \multirow{2}{*}{\multicolumn{2}{|c|}{$\begin{array}{l}\text { Roughness } \\
\text { MarSurf GD } 120\end{array}$}} \\
\hline & & & \\
\hline Lens & $20 x$ & $\lambda \mathrm{s}$ & $2.5 \mu \mathrm{m}$ \\
\hline$\lambda s$ & $2.5 \mu \mathrm{m}$ & $\lambda c$ & $0.8 \mathrm{~mm}$ \\
\hline$\lambda c$ & $0.8 \mathrm{~mm}$ & $\mathrm{n}_{\text {Measure. }}$ & 5 \\
\hline
\end{tabular}

b)

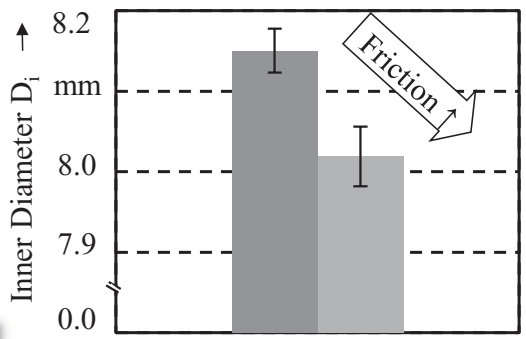

$$
\begin{aligned}
& \text { Ring compression test } \\
& \mathrm{n}=3 \\
& \mathrm{DC} 04\left(\mathrm{~s}_{0}=2 \mathrm{~mm}\right) \\
& \text { Beruforge } 150 \mathrm{DL}
\end{aligned}
$$

Figure 8. a) Topography and roughness and b) results of ring compression tests of initial surfaces compared to a blasted surfaces.

tribological conditions and the potential to influence the material flow by an adaption of the friction [25]. Due to the special load conditions in SBMF a local adaption of the tribological conditions fitted to the respective load states is a promising approach to control the material flow and thus to improve the process result.

The surface of workpiece and die are main parts of the tribological system beneath lubricant and load conditions. Due to this fact modified surfaces, so-called tailored surfaces are a suitable approach to influence the friction conditions. In general tailored surfaces are defined as process adapted semifinished workpieces or tools with geometrically determined structures in defined patterns [26]. The local adjustments of the surface can be realised on the workpiece and/or on the tool of SBMF processes. Based on the fundamental requirements regarding the tribological conditions in SBMF, milled [27] and coated surfaces [28] could be identified in former investigations as suitable methods for tool-sided adaptions. For the workpiece-sided modification micro structuring and abrasive blasting of the surface are suitable methods to generate a gradient in friction conditions [26]. In addition, a combination of tool- and workpiece-sided adaption is possible.

For a comprehensive analysis of the effectiveness of tailored surfaces in a first step the investigation of the tribological conditions of the respective tailored surfaces is necessary. To analyse friction, a test methodology consisting of the three laboratory friction tests strip drawing test, pin extrusion test and ring compression test with different load conditions adapted to the process conditions in SBMF has been developed. Further information on the test methodology can be found in [29]. Figure 8 exemplarily illustrates the topography and the friction conditions for a workpiece-sided adaption of the surface by abrasive blasting. The higher roughness, shown in Fig. 8a; of the blasted surface will increase the friction, as exemplarily shown by the results of the ring compression test in Fig. 8b. Thus, this example could demonstrate the effectiveness of tailored surfaces as a method to influence the tribological conditions and in a further step the material flow.

Recent studies have revealed the potential for an improvement of the product quality for different SBMF processes by a local increase of the friction. Referring to the SBMF processes and their process limits described in chapter 3.1 the effectiveness of tailored surfaces for both processes is presented.

For the described single-stage process combination of deep drawing and upsetting the effectiveness of workpiece-sided abrasive blasting could be verified numerically and experimentally in former investigations [30]. The main process limit is the material flow from the cup wall into the bottom, which results in local thickening of this area. In consequence, the material is not any longer available 
a)

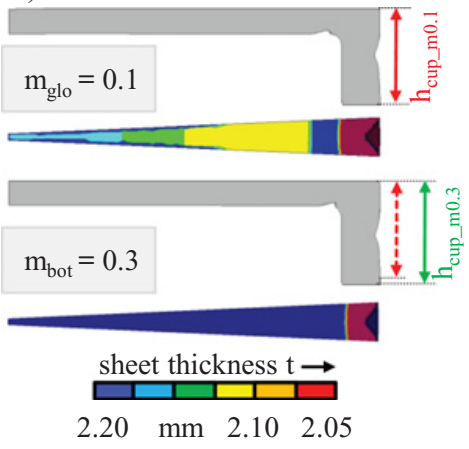

b)

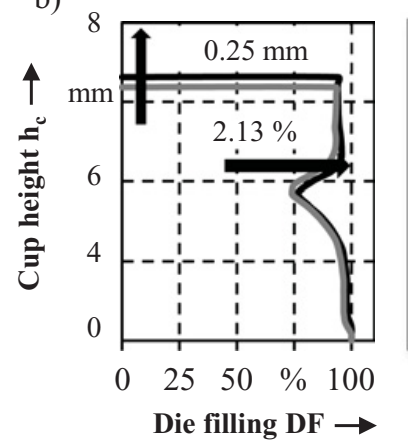

— Tailored surfaces

- Conventional blank

Upsetting force $1,000 \mathrm{kN}$

Clamping force $400 \mathrm{kN}$

DC04 Beruforge 150 DL

Figure 9. a) Numerical feasibility study and b) results of experimental verification of the effectiveness of workpiece-sided abrasive blasting.

in the cup wall to realise an adequate die filling of the gear teeth. By using a numerical feasibility study, requirements for the local adaption of the tribological conditions have been identified. The results revealed that by increasing the friction factor in the area of the cup bottom $\mathrm{m}_{\text {bot }}$ the material flow, which is directed to this area, decreases. As a consequence, the material remains in the cup wall resulting in an improved die filling of the gear teeth and an increased cup height compared to global constant friction conditions $\mathrm{m}_{\mathrm{glo}}$, see Fig. 9a. The experimental verification, shown in Fig. 9b, revealed an increase of the cup height by $0.25 \mathrm{~mm}$ and a $2.13 \%$ improvement of the die filling for the DC04 sheet by using workpiece-sided abrasive blasting on both sided of the investigated samples [31]. Thus, the increase of the friction in the area of the cup bottom decreased the material flow directed to this area and extends the limits for this kind of SBMF process.

Additionally the benefit of tailored surfaces for cold forging of functional elements out of the sheet plane to produce a component with a circumferential gearing consisting of elements with alternating rectangular and triangular shape, as showed in chapter 3.1, should be presented. For this kind of process the effectiveness of combined workpiece- and tool-sided adaption of the surface has been analysed to realise a higher gradient in friction conditions. Therefore, additionally to workpiece-sided abrasive blasting, a structure using high-feed milling produced by using a milling tool geometry with a straight cutting edge has been applied. With the help of a numerical feasibility study a methodology for the local adaption of the friction conditions $\mathrm{m}_{\text {loc }}$ could be identified, see Fig. 10a. An increase of the friction next to the cavities will reduce a material flow backwards into the sheet plane. Thus, more material will flow into the cavities and increases the heights of the functional elements. Figure 10b compares the die filling for locally adapted friction conditions $\mathrm{m}_{\mathrm{loc}}$ compared to global constant friction conditions $\mathrm{m}_{\text {glo }}$ for a conventional blank between workpiece and die. For both functional elements a significant increase of the die filling by using tailored surfaces can be detected.

Overall, it can be stated that locally adapted tribological conditions by using tailored surfaces are a promising approach to influence the material flow in SBMF processes. Thus, the process limits can be extended, which supports a further development of SBMF.

\subsubsection{Application of process adapted semi-finished parts for directing the material flow}

Besides the local modification of the tribological conditions the application of process adapted semifinished parts, so called tailored blanks, is another solution for controlling the material flow in sheetbulk metal forming processes. Tailored blanks are characterized by a local variation of sheet thickness or mechanical properties to be specifically designed for their field of application [1]. The tooling concept 
a)

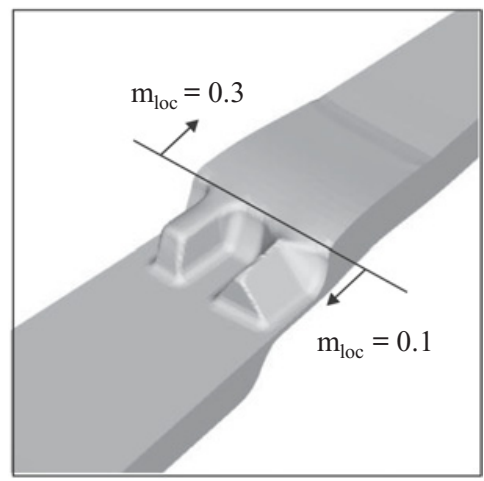

b)

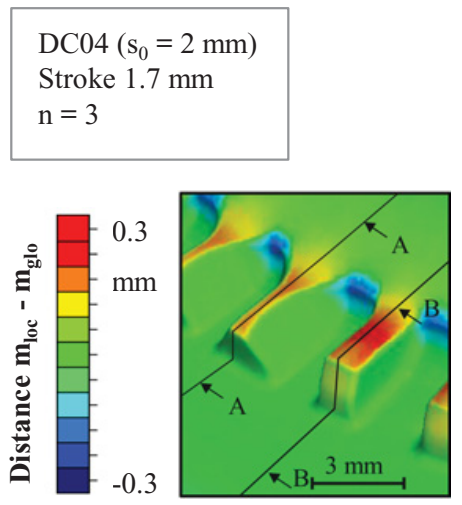

Triangular A - A

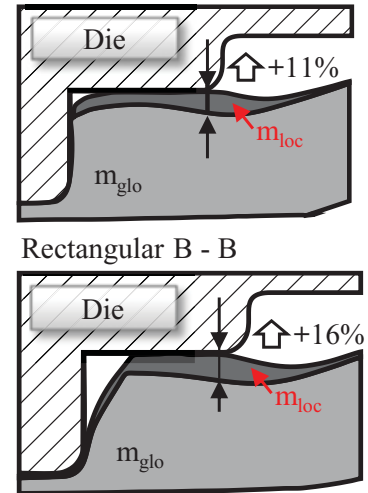

Figure 10. a) Numerically defined requirements and b) evaluation of the effectiveness of tailored surfaces on the die filling.
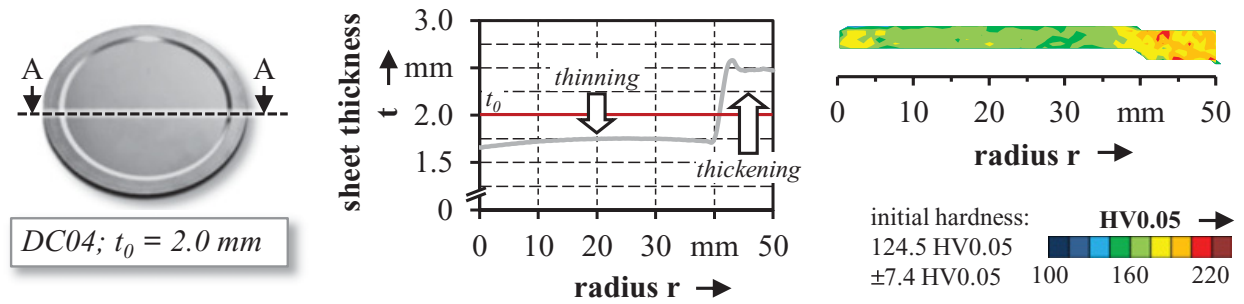

Figure 11. Process adapted semi-finished parts with locally adapted material distribution manufactured by orbital forming.

for an orbital forming process as presented in [32] enables the manufacturing of tailored blanks as depicted in Fig. 11 with a relocation of the material from the inner centre to the outside area and thus a local increase of the sheet thickness necessary for a subsequent processing. In addition to the adaption of the geometric properties of tailored blanks regarding their field of application, a modification of the mechanical properties can be realized as well. Regarding the presented orbital forming process, the forming results in a strain-hardening of the material with the highest local values in areas of interest for a subsequent forming of functional elements.

Applying tailored blanks in the single stage deep drawing and upsetting process presented above results in improved properties of the final geared component, as depicted in Fig. 12. Regarding the final geometry of the gearing, tailored blanks with locally adapted sheet thickness distributions and increased hardening lead to a reduced buckling of the cup wall which can be measured by an improved mould filling. Furthermore, the cup height can be increased about $\Delta \mathrm{h}_{\mathrm{c}}=2.2 \mathrm{~mm}$ compared with a conventional blank of $\mathrm{t}_{0}=2.0 \mathrm{~mm}$ [33]. This is caused by the higher sheet thickness and thus more material in this outer area of the tailored blanks compared to the conventional blank. In addition, the pre-hardening of the tailored blanks by the orbital forming process leads to less material flow in the cup bottom. As a consequence, more material remains in the cup wall. The strain-hardening of the tailored blanks restricts the undesired material flow from the cup wall around the corner into the cup bottom.

The application of process adapted semi-finished parts to control the undesired radial material flow and thus improve the forming of functional elements for the cold forging process presented above is exemplarily shown for one of each specimen in Fig. 13. The tailored blanks manufactured by orbital 

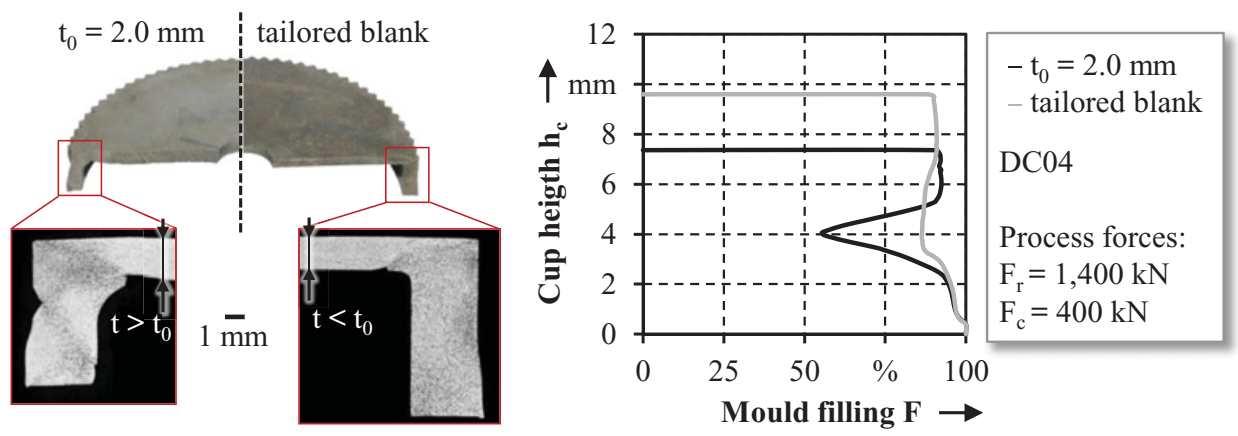

Figure 12. Application of orbital formed tailored blanks for the manufacturing of thin-walled cups with an external gearing.
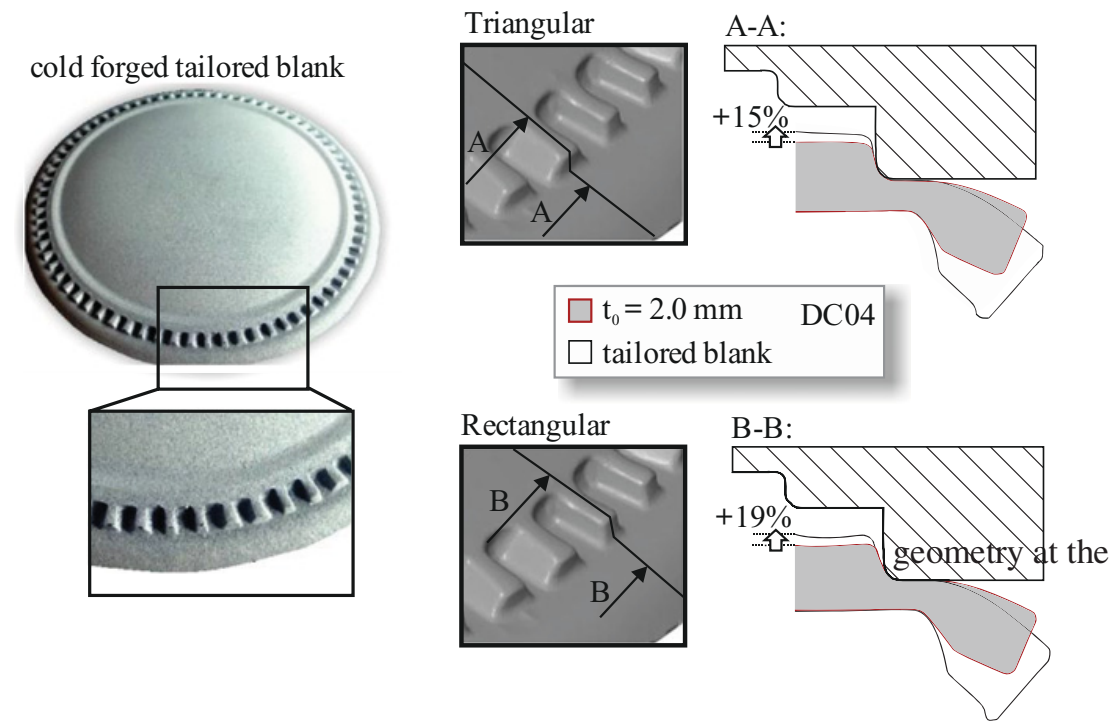

Figure 13. Profile comparison of functional elements of rectangular and triangular shape.

forming with their properties shown in Fig. 11 were used for this investigation. The functional elements formed by the cold forging process are at the same radial position as the thickening zone of the tailored blanks. In comparison with conventional unformed blanks with $\mathrm{t}_{0}=2.0 \mathrm{~mm}$, the use of orbital formed tailored blanks results in an average height increase of about $19 \%$ for the rectangular element and about $15 \%$ for the triangular element caused by the strain-hardened material as well as the additional material in this area for the tailored blanks. The application of the tailored blanks leads to an improvement of the forming of the functional elements and reduction of the undesired radial material flow in the centre and to the outside. However, the higher sheet thickness and thus increase of material in the outer zone results in a higher bending of the final geometry at the edge.

Regarding lightweight aspects, a pre-distribution of the material as well as an additional strainhardening during manufacturing, the application of tailored blanks in sheet-bulk metal forming processes can be used to control the material flow in subsequent processes. Their application results in an improved forming of functional elements and is a promising approach for the further development of SBMF processes. 


\section{Summary and outlook}

Considering modern demands like improved material efficiency and shortened process chains, the application of bulk forming operations on sheet metals enables the manufacturing of complex lightweight components with integrated functional elements. Due to the increased complexity of these parts with locally varied forming zones, the control of the material flow to ensure the requested quality of the components is crucial. Regarding two exemplarily presented sheet-bulk metal forming processes, the challenges of an uncontrolled material flow are presented. Following, two innovative solutions for controlling and directing the material flow in both processes are shown: the local adaption of the tribological conditions and the application of process-adapted semi-finished parts. Both methods have been successfully applied resulting in improved properties of the components. For current and future research, the focus will be on the investigations of the complete process chain. Starting with the initial blank, next the forming of tailored blanks and application of tailored surfaces and the subsequent manufacturing of functional components. This will be done in experimental as well as numerical methods with investigations regarding the material behaviour in terms of hardening and damage.

This work was supported by the German Research Foundation (DFG) within the scope of the Transregional Collaborative Research Centre on sheet-bulk metal forming (CRC/TR 73) in the subprojects A1, A2 and C1.

\section{References}

[1] H.E. Friedrich, Leichtbau in der Fahrzeugtechnik, Springer Vieweg, Wiesbaden, Germany (2013)

[2] R. Golloch, Downsizing bei Verbrennungsmotoren - Ein wirkungsvolles Konzept zur Kraftstoffverbrauchssenkung, Springer, Berlin, Germany (2005)

[3] M. Merklein, J. M. Allwood, B.-A. Behrens, A., Brosius, H. Hagenah, K. Kuzman, K. Mori, A.E. Tekkaya, A. Weckenmann, Bulk forming of sheet metal, Annals of the CIRP 61, 2, pp. 725-745 (2012)

[4] M. Merklein, A.E. Tekkaya, A. Brosius, S. Opel, J. Koch, Overview on Sheet-Bulk Metal Forming Processes, Proceedings of the 10th International Conference on Technology of Plasticity, pp. 1109-1114 (2011)

[5] DIN 8582, Manufacturing processes forming - Classification; Subdivision, terms and definitions, alphabetical index (2003)

[6] M. Merklein, H. Hagenah, T. Schneider, Sheet-Bulk Metal Forming Processes - State of the Art and its Perspectives. TTP 2013 - Tools and Technologies for Processing Ultra High Strength Materials, pp. 197-204 (2013)

[7] G. Herold, S. Abdel-Kader, Einfluß der Prozessparameter beim Drückwalzen auf den Werkstoffflu $\beta$ und die Produktqualität, Proceedings 5. Sächsische Fachtagung Umformtechnik, 26, pp. 1-15 (1998)

[8] T. Altan, A.E. Tekkaya, Sheet Metal Forming Processes and Applications, ASM International, 978-1-61503-844-2 (2012)

[9] Y. Xu, S.H. Zhang, P. Li, K. Yang, D.B. Shan, Y. Lu, 3D Rigid-Plastic FEM Numerical Simulation on Tube Spinning, Journal of Material Processing Technology 113, pp. 710-713 (2001)

[10] R. Kopp, Der Werkstoffflu beim Dreirollen-Drückwalzen, Archiv für das Eisenhüttenwesen 5, pp. 397-404 (1972)

[11] P. Groche, D. Fritsche, Application and Modelling of Flow Manufacturing Processes for Internally Geared Wheels, International Journal of Machine Tools \& Manufacture 46, pp. 1261-1265 (2006) 
[12] C.C. Wong, A. Danno, K.K. Tong, M.S. Yong, Cold Rotary Forming of Thin-Walled Component from Flat-Disc Blank. Journal of Materials Processing Technology 208, pp. 53-62 (2008)

[13] M. Runge, Drücken und Drückwalzen, Verlag moderne Industrie AG, Landsberg, Germany. (1993)

[14] Winkelmann MSR Technology GmbH und Co. KG, http://winkelmann-group.de/ produkte/flowforming/ (Update March 23th 2015)

[15] Z. Marciniak, A rocking-die technique for cold-forming operations, Machinery and production engineering 117, pp. 792-797 (1970)

[16] J.R. Maicki, Orbital forging, Metallurgia and Metal Forming, pp. 265-269 (1977)

[17] K. Lange, Umformtechnik, Handbuch für Industrie und Wissenschaft, Band 2: Massivumformung, 2nd edition. Springer-Verlag, Berlin, Germany (1988)

[18] H.-K. Oh, S. Choi, A Study on Center Thinning in the Rotary Forging of a Circular Plate, Journal of Materials Processing Technology 66, pp. 101-106 (1997)

[19] X. Han, L. Hua, Investigation on contact parameters in cold rotary forging using a 3D FE method, Int. Journal of Advanced Manufacturing Technology 62, 9-12, pp. 1087-1106 (2012)

[20] P.M. Standring, Characteristics of Rotary Forging as an Advanced Manufacturing Tool, Proceedings of the Institution of Mechanical Engineers Part B 215, pp. 935-945 (2001)

[21] Heinrich Schmid Maschinen- und Werkzeugbau AG, Umformtechnik, 2, pp. 28-31 (2006)

[22] J.J. Sheu, C.H. Yu, The Cold Orbital Forging Die and Process Design of a Hollow-ring Gear Part; Proceedings of the 35th International Matador Conference 6, pp. 111-114 (2007)

[23] T. Schneider, M. Merklein, Manufacturing of geared sheet metal components by a single-stage Sheet-bulk metal forming process, Proc. Conf. Competitive Manufacturing, pp. 177-182 (2013)

[24] D. Gröbel, J. Koch, U. Vierzigmann, U. Engel, M. Merklein, M, Investigations and approaches on material flow of non-uniform arranged cavities in sheet bulk metal forming processes, Procedia Engineering 81, pp. 401-406 (2014)

[25] Y. Oyachi, J.M. Allwood, Characterizing the Class of Local Metal Sheet Thickening Processes, Steel research international 10, pp. 1025-1030 (2011)

[26] U. Vierzigmann, M. Merklein, U. Engel, Tailored Surfaces in Sheet-Bulk Metal Forming, Proc. 4th ICTMP Int. Conf. on Tribology im Manuf. Processes 2, pp. 541-550 (2010)

[27] R. Hense, P. Kersting, U. Vierzigmann, M. Löffler, D. Biermann, M. Merklein, C. Wels, HighFeed Milling of Tailored Surfaces for Sheet-Bulk Metal Forming Tools, Production Engineering, (DOI) 10.1007/s11740-014-0597-0: Springer (2014)

[28] H. Hetzner, W. Tillmann, S. Tremmel, J. Herper, Tribologische Dünnschichten für die Blechmassivumformung, 1. Workshop Blechmassivumformung, pp. 139-158 (2011)

[29] U. Vierzigmann, J. Koch, M. Merklein, U. Engel, Material Flow in Sheet-Bulk Metal Forming, Key Eng. Mater. 504-506, pp. 1035-1040 (2012)

[30] T. Schneider, U. Vierzigmann, M. Merklein, Analysis of Varying Properties of Semi-finished Products in Sheet-bulk Metal Forming of Functional Components, NUMISHEET 2014: 9th Int. Conf. and Workshop on Numerical Simulation of 3D Sheet Metal Forming Processes, pp. 930-933 (2014)

[31] M. Löffler, T. Schneider, U. Vierzigmann, U. Engel, M. Merklein, Locally Adapted Tribological Conditions as a Method for Influencing the Material Flow in Sheet-Bulk Metal Forming Processes, Key Engineering Materials 639, pp. 267-274 (2015)

[32] S. Opel, Herstellung prozessangepasster Halbzeuge mit variabler Blechdicke durch die Anwendung von Verfahren der Blechmassivumformung, Meisenbach Verlag, Erlangen, Germany (2013)

[33] T. Schneider, M. Merklein, Sheet-bulk metal forming - potential and challenges of a new class of forming processes, Proceedings of PLASTICITY '15: The Twenty First International Symposium on Plasticity and its Current Applications, pp. 169-171 (2015) 